\title{
Sero-prevalence study to determine the effectiveness of Peste de Petits Ruminants vaccination in Somalia
}

\author{
Sophycate Njue ${ }^{1 *}$ DD, Khalid Saeed ${ }^{1}$, Seiffuddin Maloo², Joan Muchai ${ }^{1}$, Cyprien Biaou $^{3}$ and Kennedy Tetu ${ }^{1}$
}

\begin{abstract}
Peste de Petits Ruminants (PPR) is an acute or sub-acute highly contagious viral disease of small ruminants caused by morbillivirus and associated with high mortality and morbidity rates in naïve populations, colossal economic losses, reduced production and productivity as well as high control costs. Sero-surveys conducted in Somalia between 2006 and 2009 revealed sero-prevalence of 6.5\% in north-western Somalia, 28.7\% in north-eastern Somalia, $32.6 \%$ in central Somalia and $37.6 \%$ in southern Somalia.

Somalia, like other countries in conflict, has limited capacity to control PPR. In this regard, Food and Agriculture Organisation of the United Nations (FAO) conducted country-wide PPR vaccination campaigns covering the five zones of Somalia, namely, Banadir, central, north-eastern, north-western and southern using a public-private partnership approach. Approximately 20 million sheep and goats constituting 60\% of the estimated Somalia national small ruminant population were targeted for vaccination in entire Somalia in 2012. Data on vaccination was captured using FAO's Form Monitoring Tool (FMT) software. The overall unit cost of PPR vaccination was estimated to be USD 0.28 per animal.

Two serological surveys were conducted before and after the vaccination campaigns where a two-stage cluster sampling methodology was used to collect sera samples for analysis. The results showed an overall increase in individual animal sero-prevalence from 62 to $76 \%$ after PPR vaccination campaign.

This paper primarily focuses on practicality of PPR control in Somalia, a conflict-affected and fragile zone, which can be adopted by other countries.
\end{abstract}

Keywords: Somalia, PPR, Vaccination, Sero-prevalence, Cost of disease control

\section{Introduction}

Peste de Petits Ruminants (PPR) is an acute or sub-acute highly contagious viral disease of small ruminants caused by morbillivirus. The disease affects both goats and sheep; however, goats are considered more susceptible than sheep (Gargadennac and Lalanne 1942). The disease is associated with high mortality and morbidity rates in naïve populations (Kaukarbayevich 2009), colossal economic losses (Couacy-Hymann et al. 1995), reduced production, productivity as well as high control costs (FAO 2010). PPR negatively affects livelihoods through diminished and complete loss of incomes and

\footnotetext{
* Correspondence: Sophycate.Njue@fao.org

${ }^{1}$ Food and Agriculture Organisation of the United Nations (FAO), Somalia

Country Office, P.O Box 30470-00100, Nairobi, Kenya

Full list of author information is available at the end of the article
}

increased vulnerability to shocks as reported during the PPR outbreak in Kenya (FAO 2009a, b). In addition, the disease is a major impediment to attaining a major global development objective to eradicate extreme poverty and hunger.

PPR was first recorded by Gargadennac and Lalanne (1942) in Cote d'Ivoire, West Africa, and has since widely spread in other parts of Africa and Asia (Taylor et al. 1990; Banyard et al. 2010; Munir et al. 2013). In the Greater Horn of Africa region, PPR outbreaks were reported in Sudan, Ethiopia, Somalia and Kenya (Diallo 1988; Roeder et al. 1994; Karimuribo et al. 2008 and Kihu et al. 2012). In Somalia, there were unconfirmed PPR outbreaks but sero-surveys conducted between 2006 and 2009 (SAHSP 2006a, b, 2009) revealed sero-prevalence of $6.5 \%$ in north-western Somalia, $28.7 \%$ in north-eastern 
Somalia, 32.6\% in central Somalia and 37.6\% in southern Somalia. Although these results are inconclusive on the frequency and distribution of PPR in Somalia, they are a good indicator of PPR virus circulation and hence PPR infection as reported by Waret-Szkuta et al. (2008) in other studies.

Somalia, like other countries in conflict, has limited capacity to control PPR. The country is constrained by inadequate physical infrastructure, insufficient financial resources and weak public sector-based veterinary service. This is further compounded by the fact that Somalia has a large small ruminant population associated with high reproductive rate, high population turnover rate and massive cross-border movements between Somalia/Ethiopia and Kenya. These factors are a major hindrance to the implementation of a coordinated PPR disease eradication programme. Past attempts by private sector actors to control PRR have not been very effective. Unpublished reports by FAO (2001) point out ad hoc vaccinations characterised by low vaccination coverage and poor coordination among the stake holders.
In response to the country's needs and in line with its mandate, FAO supported the Somalia Government in developing a 15-year phased strategy for control of PPR with possible eradication (FAO 2011a, b, c) under a livelihood support programme. The strategy is in line with the FAO/World Animal Health Organisation (OIE) global strategy for the control and eradication of PPR (FAO/OIE, 2015). The strategy outlines the four stages of PPR eradication in which stage 1 is assessment stage, which includes different activities aiming to better understand the epidemiological situation of PPR, followed by stage 2 of country-wide vaccination for control of PPR virus circulation. Stage 3 mainly builds on stages 1 and 2 and aims at progressive control to a point of eradication by focussing on PPR vaccination backed by disease surveillance and reporting in epidemiologically important areas. In stage 4, final eradication is considered. Somalia implemented a country-wide PPR vaccination campaign between 2012 which places the country at stage 2 of the eradication strategy.

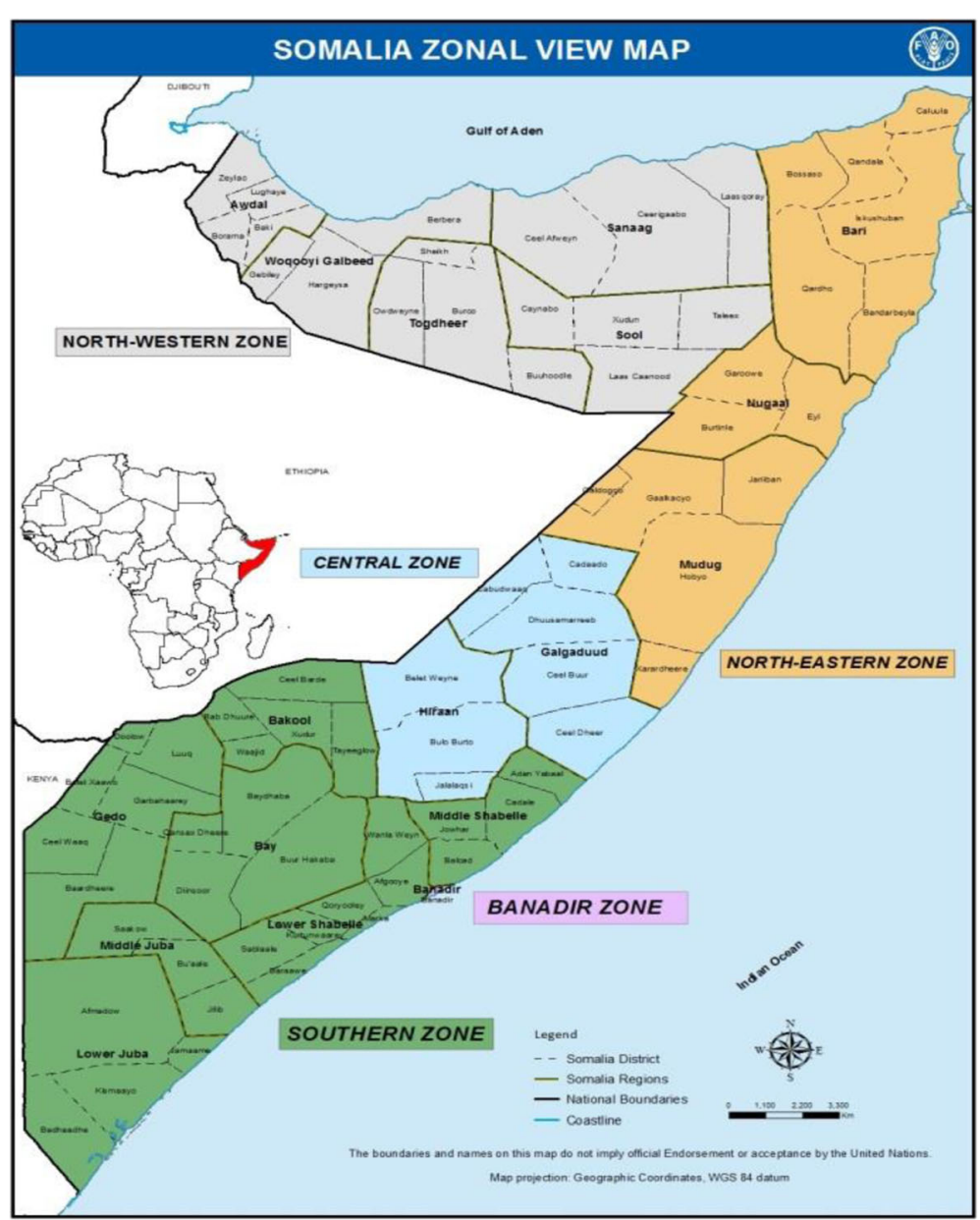

Figure 1 Map of Somalia showing the different zones 
This paper seeks to contribute to the pool of knowledge on control of PPR in countries undergoing prolonged conflicts and also those with limited public veterinary structures, considering that there is limited published information available. The paper describes the mass PPR vaccination campaigns within a livelihood support programme framework, the suitability of vaccination as a tool for control of PPR virus circulation, and also discusses the practical implications of such a strategy in conflict-affected and fragile countries.

\section{Study area}

The study covered entire Somalia which was clustered into five zones of Banadir, central, north-eastern, northwestern and southern Somalia. The selection was based on sheep and goat population density, prevalence of Transboundary Animal Diseases (TADs) and mapping of FAO-led livestock interventions.

\section{Methods}

\section{Selection of areas to target for PPR vaccination}

The PPR vaccination campaigns were conducted in the five zones of Somalia namely Banadir, central, north-eastern, north-western and southern as shown in Figure 1. The entire country was chosen because first, there were many isolated PPR disease outbreaks reported throughout the country (Wamwayi et al. 1995). Second, sheep and goats are kept under agro-pastoral and pastoral systems where they move freely within the country and across borders, thus increasing the likelihood of PPR spread in times of outbreaks. Third, PPR is endemic in neighbouring Kenya and Ethiopia which puts all the animals in Somalia at risk.

\section{Selection of targeted population}

Approximately 20 million sheep and goats constituting $60 \%$ of the estimated Somalia national small ruminant population were targeted for vaccination in entire Somalia in 2012. Table 1 shows the distribution of sheep and goats targeted for PPR vaccination by geographic zones.

The number of small ruminants targeted for PPR vaccination at the national level was based on the

Table 1 Number of sheep and goats targeted during PPR vaccination campaign in Somalia 2012

\begin{tabular}{ll}
\hline Zones & Total animal targeted \\
\hline Banadir & 150,000 \\
Central Somalia & $6,000,000$ \\
Southern Somalia & $6,000,000$ \\
North-eastern Somalia & $4,000,000$ \\
North-western Somalia & $4,000,000$ \\
Total & $20,150,000$ \\
\hline
\end{tabular}

number of vulnerable livestock-keeping households and available budget. The numbers at the zonal level were determined by the small ruminants' population density, geographic distribution and frequency of reported PPR cases. All the sheep and goats belonging to vulnerable livestock-keeping households were purposively targeted apart from those that were sick, below three months of age or had been vaccinated previously. The age of the animals was determined through interviews with targeted livestock owners and was further corroborated by use of dental formula. The vaccination history was provided by the livestock owners.

\section{Procurement of goods and services}

There was procurement of cold chain equipment and PPR vaccines as well as constitution of vaccination teams prior to vaccination campaigns. The cold chain equipment consisted of large-sized and medium-sized deep freezers, cool boxes and vaccine carriers. The freezers were solar powered and had provision for temperature regulation. The temperatures could be adjusted for storage of vaccine and serum sample as well as making ice blocks that were used for the cool boxes. In addition, approximately 20 million doses of freezedried live attenuated PPR vaccine strain Nigeria 75/1 strain were competitively procured from a Jordan BioIndustries Center(JOVAC ${ }^{\circ}$ ) with support of FAO. This vaccine is certified by the African Union's Pan African Veterinary Vaccine Centre (AU/PANVAC), the only organisation mandated to provide international independent quality control of veterinary vaccines used in African countries. The vaccines were delivered directly in Somalia after which they were inspected, before distribution for storage in the cold chain hubs. The vaccines were stored and transported at between +2 and $+8{ }^{\circ} \mathrm{C}$, from the hubs to the vaccination sites in cool boxes and vaccine carriers. The cool boxes and vaccine carriers were replenished with ice blocks every two to three days. The Livestock Professional Associations (LPAs), namely South West Livestock Professional Association (SOWELPA, Central Region Livestock Professional Association (CERELPA), Banadir Region Livestock Professional Association (BENALPA) and Ministries responsible for livestock in north-eastern and northwestern zones, were also identified and contracted to conduct PPR vaccination campaigns based on technical expertise, past records of successful implementation of vaccination campaigns and operational presence.

\section{Organisation of PPR vaccination campaigns}

The vaccination team leaders were taken through a oneday refresher training on planning and management of PPR vaccination campaigns. The record keepers were trained on vaccination field data capture using Form Monitoring Tool (FMT) software for a period of 60 
working days. Further, the team members were also taken through a refresher training on procedures of serum sample collection and proper sample labelling. During this training, emphasis was put on the importance of cold chain management. These trainings were conducted by FAO technical staff in Garowe for northeastern zone and Hargeisa for north-western zone. For the Banadir, central and southern zones, the trainings were conducted in Nairobi, Kenya.

The vaccination teams were equipped with cold chain equipment, vaccines, veterinary supplies and equipment, and facilitated with transport. They were also provided with pre-designed data entry sheets and laptops for the management of surveillance and vaccination data. Each team prepared a detailed work plan covering the entire vaccination period. The plans were shared with clan leaders, village elders and local authorities during community awareness creation and sensitization. The awareness creation fora provided an opportunity to emphasise the importance of the vaccination campaign and collect important village contact details.

\section{Implementation of PPR vaccination campaign}

The vaccination teams were deployed in the field from March to May 2012 for a period of 60 working days. Each team was required to vaccinate a minimum of 2,500 sheep and goats daily apart from Banadir region which had lower daily targets of 500 animals. Banadir was exceptional because it is peri-urban, and there was a challenge of gathering animals together for vaccination.

Full consent of the Somali veterinary authorities was sought before carrying out the PPR vaccination campaign, collection of disease surveillance data and the serological surveys. The authorities granted permission to collect and test field laboratory samples. High levels of quality and integrity were observed during the fieldwork. The livestock keepers were also sensitised prior to the field interventions after which they voluntarily presented and participated in the vaccination, as well as collection of serum samples from sheep and goats.

The field activities were monitored by officers of the Ministries responsible for livestock in the five targeted zones. The process entailed visiting vaccination sites and enquiring from community leaders and targeted households about the vaccination campaign and serological survey. Likewise, FAO technical staff and field monitors carried out independent monitoring through field visits, collection of data using pre-designed questionnaires and call centre surveys. This was in addition to progress reports and photographic evidence on the implementation of the activities submitted by the vaccination teams.

\section{Serological surveys}

Two serological surveys were conducted. The first one was conducted in March 2012 and the second in September 2012. The sample size was calculated based on the percentage of the total number of animals targeted for vaccination. A two-stage cluster sampling methodology was used whereby a total of 18,377 sera samples were randomly collected from small ruminants, representing $0.1 \%$ of the total number of the animals targeted for vaccination. Table 2 illustrates the number of serum samples taken during the serological surveys.

Blood was drawn from the jugular vein in plain 10-ml vacutainer tubes, kept in a cool place for up to $24 \mathrm{~h}$ to allow for clotting. Then, sera were decanted into two aliquots which were then transferred into 5 -ml pre-labelled cryovials. The cryovials were properly labelled to ensure quick identification of the sample by region, district, team and chronological numbering of every sample. Every sample collected was recorded in pre-designed recording sheets. Sera were then stored in ice-filled cool boxes for a period of two to three days until their transfer to deep freezers where they were stored at $-20{ }^{\circ} \mathrm{C}$. The sera were subsequently airlifted from Somalia to AU-PANVAC laboratories in Ethiopia in August 2014 for serological analysis.

Table 2 Number of serum samples taken before and after PPR vaccination campaigns in Somalia, 2012

\begin{tabular}{lllll}
\hline Zones & Number of animals vaccinated & $\begin{array}{l}\text { Number of pre-vaccination } \\
\text { sera samples collected }\end{array}$ & $\begin{array}{l}\text { Number of post-vaccination } \\
\text { sera samples collected }\end{array}$ & \begin{tabular}{l} 
Total number of sera samples \\
\hline Banadir
\end{tabular} \\
Central Somalia & 148,100 & 88 & 168 & 256 \\
Southern Somalia & $5,824,724$ & 2,294 & 3,750 & 6,044 \\
North-eastern Somalia & $5,953,821$ & 2,996 & 4,711 & 7,707 \\
North-western Somalia & $3,989,736$ & 1,056 & 1,408 & 2,464 \\
Total & $19,666,847$ & 1,300 & 606 & 1,906 \\
\hline
\end{tabular}


The Competitive Enzyme-Linked Immunosorbent Assay (c-ELISA), the test recommended by OIE (2004), was used for PPR diagnoses. Serum samples were tested for IgG PPR antibodies using monoclonal antibody-based c-ELISA directed against nucleoprotein ( $\mathrm{N}$ protein) as described by Libeau et al. (1995). Any serum samples with a percentage inhibition value equal to or greater than $50 \%$ were considered positive for PPR. The laboratory test results were released in January 2015.

\section{Data analysis}

The vaccination data was analysed using Form Monitoring Tool (FMT) software and thereafter exported to Microsoft ${ }^{\oplus}$ Excel 2013 (Microsoft Inc. USA) for the computation of summary statistics which were presented in form of tables. The Ascent ${ }^{\text {tw }}$ Software from Thermo Scientific $^{\mathrm{Tm}}$ was used to generate sero-prevalence results from the ELISA reader. Data were then exported to Microsoft ${ }^{\circ}$ Excel 2013 (Microsoft Inc. USA), to enable generation of preliminary sero-prevalence frequency tables. The sero-prevalence estimates were derived using the formula:

$$
\mathrm{P}=(y / n) \times 100
$$

where $y$ denoted the total number of samples testing positive for PPRV antibodies and $n$ was the sample size (Thrusfield 2005).

This formula was applied in calculating zone-specific as well as country-wide sero-prevalence values. Subsequent analyses for homogeneity between pre- and post PPR vaccination sero-prevalence values was done using Mantel Hensel test in Stata ${ }^{\circ}$ Statistical Software, Release 13 (StataCorp 2013). The Mantel-Haenszel chi-square value tests the null hypothesis that the individual stratum odds ratios are all equal to one versus the alternative hypothesis that at least one odds ratio is different from unity.

\section{Estimation of the PPR vaccination costs}

The estimation of PPR vaccination cost was based on the requirements that included purchase of PPR vaccines, cold chain equipment, vaccination supplies and equipment. Other requirements that were costed included transport for the vaccination teams, time dedicated to vaccination campaigns by the vaccination teams, capture of field data, analyses of serum samples, monitoring the vaccination campaigns and cold chain maintenance.

Hence:

$$
\begin{aligned}
& \text { Total cost of the vaccination }(\mathrm{TCV}) \\
& =(\text { Cost of establishing and maintaining cold chain }) \\
& \\
& +(\text { Cost of procuring PPR vaccines }) \\
& \quad+(\text { Cost of procuring vaccination supplies and equipment }) \\
& \quad+(\text { Cost of services for vaccine delivery })
\end{aligned}
$$

The unit cost of vaccination was calculated as follows:

Total cost of vaccination (TCV)/number of animals vaccinated.

\section{Results \\ Positioning of vaccination teams, cold chain equipment and $P P R$ vaccines}

A total of 140 teams from livestock professional associations and Ministries responsible for livestock were deployed in the five zones to conduct the vaccination campaign. Each team was comprised of five members that included four livestock professionals who were either veterinarians or veterinary paraprofessionals and a record keeper. The team leaders were veterinarians. The Federal Government of Somalia, represented by the Ministry of Livestock, Forestry and Range (MoLFR), supervised and monitored the vaccination campaign implemented by SOWELPA, CERELPA and BENALPA. The cold chain equipment was distributed in pre-determined strategic locations closer to vaccination sites prior to commencement of vaccination. The distribution of the teams, the PPR vaccine doses and the cold chain equipment is shown in Tables 3 and 4.

Table 3 The distribution of PPR vaccine doses in the five zones according to the implementing organisations and public institutions, 2012

\begin{tabular}{llll}
\hline Zones & Implementing organisations/institutions & Number of vaccination teams & PPR vaccine doses distributed \\
\hline Banadir & Banadir Livestock Professional Association (BENELPA) & 10 & 150,000 \\
Central Somalia & Central Livestock Professional Association (CERELPA) & 45 & $6,000,000$ \\
North-eastern Somalia & Ministry of Livestock and Animal Husbandry (MoLAH) & 20 & $4,000,000$ \\
North-western Somalia & Ministry of Livestock (MoL) & 20 & $4,000,000$ \\
Southern Somalia & South West Livestock Professional Association (SOWELPA) & 45 & $6,000,000$ \\
Total & & 140 & $20,150,000$ \\
\hline
\end{tabular}


Table 4 Distribution of cold chain equipment in the five zones of Somalia, 2012

\begin{tabular}{llllll}
\hline Zone & $\begin{array}{l}\text { Location of cold } \\
\text { chain hub }\end{array}$ & $\begin{array}{l}\text { Large-sized deep } \\
\text { freezers (336 I) }\end{array}$ & $\begin{array}{l}\text { Medium-sized deep } \\
\text { freezers (280 I) }\end{array}$ & $\begin{array}{l}\text { Cool } \\
\text { boxes (22 I) }\end{array}$ & $\begin{array}{l}\text { Vaccine } \\
\text { carriers (1.6 I) }\end{array}$ \\
\hline Banadir & Mogadishu & 6 & 5 & 0 & 7 \\
Central Somalia & Belet Weyne & 6 & 6 & 15 & 5 \\
North-eastern Somalia & Garowe & 8 & 8 & 4 & 0 \\
North-western Somalia & Hargeisa & 8 & 8 & 4 & 6 \\
Southern Somalia & Baidoa & 7 & 8 & 15 & 3 \\
Total & & 35 & 35 & 38 & 26 \\
\hline
\end{tabular}

\section{PPR vaccination coverage}

The vaccination campaign implemented in the five zones of Somalia achieved an overall vaccination coverage of $97.6 \%(19,666,847$ out of $20,150,000)$ goats and sheep. The highest vaccination coverage was $99.7 \%$ in northwestern Somalia whereas the lowest was $95.4 \%$ in central Somalia zone. The high vaccination coverage was as a result of limited vaccine losses during the vaccination campaigns. This was achieved through sensitisation of livestock-keeping communities to present target animals in pre-identified vaccination sites and pre-positioning of cold chains in strategic field location for vaccine storage during the vaccination campaigns. The vaccination sites were mainly watering points and grazing sites. Table 5 provides a summary of vaccination coverage for each of the five zones.

\section{Analyses of serology results}

There was an increase in sero-prevalence after PPR vaccination campaign. The serology results revealed an overall sero-prevalence of $62 \%(4,792 / 7,734)$ before vaccination and $76 \%(8,089 / 10,643)$ after vaccination at $(p<005)$ (Table 6). The pre-vaccination sero-prevalence was highest in north-eastern zone (74\%) and lowest in Banadir (39\%), whereas the post-vaccination seroprevalence was highest in central Somalia zone (87\%) and lowest in Banadir (58\%).

The results of Mantel Hensel test of homogeneity at 95\% confidence interval were as follows:

Test of homogeneity Mantel-Haenszel Chi2 (1) = 753.57

Table 5 Analyses of PPR vaccination coverage in sheep and goats in the five zones of Somalia, 2012

\begin{tabular}{llll}
\hline Zones & $\begin{array}{l}\text { Total animal } \\
\text { targeted }\end{array}$ & $\begin{array}{l}\text { Total animal } \\
\text { vaccinated }\end{array}$ & $\begin{array}{l}\text { \% coverage of } \\
\text { the targets }\end{array}$ \\
\hline Banadir & 150,000 & 148,100 & 98.7 \\
Central Somalia & $6,000,000$ & $5,824,724$ & 95.4 \\
Southern Somalia & $\mathbf{6 , 0 0 0 , 0 0 0}$ & $5,953,821$ & 99.2 \\
North-eastern Somalia & $4,000,000$ & $3,750,466$ & 96.2 \\
North-western Somalia & $4,000,000$ & $3,989,736$ & 99.7 \\
Total & $20,150,000$ & $19,666,847$ & 97.6 \\
\hline
\end{tabular}

$$
\operatorname{Pr}>\operatorname{chi}^{2}=0.0000
$$

Since the confidence intervals did not include 1 , it implied that the differences in antibody levels preand post PPR vaccination could not have been by chance. There was significant difference in seroprevalence values pre- and post PPR vaccination at 95\% confidence level.

\section{Costs of PPR vaccination}

The overall cost of vaccination entailed the cost of contract time by the vaccination teams, vaccines, transport, cold chain, field equipment, vaccination equipment and other supportive services such as monitoring, data and serum collection. This was costed per animal vaccinated as tabulated in Table 7.

The cost of contract service during vaccination was USD 2,770,160 which constituted nearly $50 \%$ of the total vaccination costs. Based on the number of sheep and goats targeted for vaccination against PPR which was $20,150,000$, the unit cost of service delivery of the vaccine per animal was USD 0.14 per animal whereas the estimated cost of a dose of PPR vaccine was USD 0.12. The overall PPR vaccination cost per animal was estimated as 0.28 USD.

\section{Discussion}

The cold chain was an important requirement from the point of manufacture, during the transportation and storage to the point of vaccine use. The cold chain equipment was appropriately positioned in the field prior to the vaccination campaign to ensure the storage temperatures of between +2 and $+8{ }^{\circ} \mathrm{C}$ were maintained. Where cold chain equipment was insufficient, prior arrangements were made to use the cold chain facilities from organisations providing health services in Somalia. To overcome challenges of electric power supply, solar-powered freezers were supplied in the five zones. Solar-powered refrigeration has been used for vaccine storage by United Nations Children Fund (UNICEF) mainly in Africa where other sources of reliable electricity are inadequate or costly (McCarney et al. 2013). 
Table 6 Analyses of PPR serum samples collected from small ruminants before and after PPR vaccination in the five zones in Somalia, 2012

\begin{tabular}{llllll}
\hline Zones & \multicolumn{2}{l}{ Pre-vaccination } & & Post-vaccination & \\
\cline { 2 - 3 } \cline { 5 - 6 } & No. of samples tested & \% PPR sero-prevalence & & No. of samples tested & \% PPR sero-prevalence \\
\hline Banadir & 88 & 39 & 73 & 3,750 & 58 \\
Central Somalia & 2,294 & 56 & 4,711 & 87 & 82 \\
Southern Somalia & 2,996 & 74 & 1,408 & 79 \\
North-eastern Somalia & 1,056 & 66 & 606 & 73 \\
North-western Somalia & 1,300 & 62 & 10,643 & 76 \\
Total & 7,734 & & &
\end{tabular}

The PPR disease control strategy in Somalia was initially though country-wide vaccination campaigns, the method prescribed for the control of PPR in endemic countries (Diallo 2004). Vaccinating a large number of animals minimises the spread of the PPR by decreasing effective contact rate. Despite the immense sociopolitical challenges existing currently in Somalia, nearly 20 million small ruminants distributed across the country were immunised achieving an overall vaccination coverage of $97.6 \%$, placing Somalia among the first countries in the Horn of Africa to implement a country-wide PPR vaccination campaign of such magnitude. This level of coverage is much higher than the average annual vaccination coverage of $15 \%$ reported to World Animal Health Organisation (OIE) by PPR-infected countries, according to a study by Jones et al. (2016). In the Greater Horn of Africa region, Kenya vaccinated an estimated two million goats and sheep against PPR in 2006 in Turkana County (Kihu et al. 2015a, b). According to studies by Singh (2011), 85.4\% vaccination coverage is necessary for control of PPR infection in sheep population.

Vaccination has been described as the preferred tool for controlling and eradicating PPR, especially in countries where it is difficult to control animal movement (Jones et al. 2016). Ideally, the PPR vaccination should be timelimited with high coverage to achieve the necessary herd immunity in high-risk areas. The PPR Global Eradication Program recommends two-year vaccination campaigns

Table 7 Analyses of estimated cost of PPR vaccination campaigns and serological Survey in Somalia, 2012

\begin{tabular}{ll}
\hline Description of activity & Amount USD \\
\hline Procurement of PPR vaccine & $2,414,040$ \\
Contract service fee for vaccine delivery & $2,770,160$ \\
Procurement and maintenance of cold chain & 392,933 \\
Serum sampling and testing & 70,522 \\
Total & $5,647,655$ \\
No. of animals targeted against PPR & $20,150,000$ \\
Cost of vaccinating one animal & 0.28 \\
\hline
\end{tabular}

following up on young animals between four months and one year in age (FAO/OIE 2015). Considering the predominant extensive and mobile livestock production systems in Somalia, vaccination is still an effective control measure of PPR despite the inherent challenges of the large sheep and goat populations, high reproductive rates exemplified by short gestation period and high twinning percentage as well as high turnover. The PPR vaccinations conducted in Somalia has reduced the disease incidence to a level where relatively small-scale targeted vaccination can be carried out in line with the time-bound PPR disease control strategy for Somalia (FAO 2011a, b, c). The large-scale vaccination has reduced the effective contact rate, thus curbing the spread of PPR among the small stock. Moreover, such vaccination campaigns have been reported to reduce the socio-economic impact of PPR (Jones et al. 2016).

The serology survey results from the analyses of 7,734 serum samples collected from sheep and goats before the PPR vaccination revealed an overall individual animal sero-prevalence of $62 \%$ with a low of $39 \%$ and a high of $74 \%$ in Banadir zone and north-eastern zone respectively. These values are high compared to those recorded in a baseline PPR sero-survey conducted by Somali Animal Health Services Project (SAHSP) in Somalia between 2001 and 2007 which gave a low of 6.5\% in northwestern zone and a high of $37.6 \%$ in southern Somalia (SAHSP 2006a, b, 2009). The overall individual animal pre-vaccination sero-prevalence was also relatively higher compared to $35.5 \%$ reported in studies by Chavan et al. (2009) in India and $46.5 \%$ Ekue et al. (1992) in Cameroon. In Ethiopia, an overall individual animal sero-prevalence of $30.9 \%$ was reported in a study by Megersaa et al., 2011. Other studies conducted in the Somali region of Ethiopia, an area under pastoral management system, gave a sero-prevalence of $21.3 \%$ at $95 \%$ confidence level (Waret-Szkuta et al. 2008).

The high pre-vaccination sero-prevalence of PPR in Somalia can be attributed to increased PPR virus circulation as illustrated by the confirmed PPR outbreaks by SAHSP between 2005 and 2009 (SAHSP 2009), taking 
into consideration that the past vaccination attempts have been on a small scale and largely uncoordinated (FAO 2001). This corroborates work by Waret-Szkuta et al. (2008) who in their study concluded that high antibody levels in small ruminant population with minimal vaccination coverage is due to a circulating PPR virus. Considering the high reproductive rate, uncontrolled movements and high turnover of small stock in Somalia, an antibody prevalence of $62 \%$ is unlikely to offer protection and prevent further epidemics.

The results of 10,643 serum samples collected after the PPR vaccination campaign showed an increase in herd immunity from 62 to $76 \%$ at $(p<005)$. There is an argument by Inter Government Authority for Development (IGAD) that due to the high annual turnover of the small ruminants, the herd immunity threshold is unlikely to increase by using repeated annual vaccination, and instead, large numbers of vaccinations should be delivered in a short time period under targeted vaccination programmes (IGAD-2014). A sero-epidemiological survey in Turkana, Kenya, by Kihu et al. (2015a, b) confirms that high demographic changes reduce the PPR herd immunity of small ruminants with introduction of naïve and vulnerable weaned kids and lambs that have decreasing maternal immunity into the already immunised herd. Studies by Ata et al. (1989) and Bidjeh et al. (n.d.) have shown that maternal antibodies in young animals are detectable up to six months of age and fall below the protection threshold level at 3.5 and 4 . 5 months in lambs and kids, respectively. Therefore, annual PPR vaccination campaigns targeting middle age group can improve the herd immunity to levels that can contain spread of the PPR disease (Kihu et al. 2015a, b). Outcomes of two studies by Singh (2011) and Balamurugan et al. (2014) elucidate that PPR mass vaccination campaigns that achieve 70 to $80 \%$ levels of herd immunity threshold break the effective transmission of the virus irrespective of the population dynamics, disparities in husbandry practices and the agro-climatic conditions affecting the pattern of disease. In essence within this herd immunity threshold range, there is sufficient proportion of immune small ruminant population for PPR virus to become stable as all the vaccinated, infected and recovered animals are protected (Balamurugan et al. 2014). The herd immunity threshold for Rinderpest, which is closely related to PPR, was estimated as 75 to $80 \%$ (Rossiter and James 1989).

There was significant difference in sero-prevalence values pre- and post PPR vaccination at $95 \%$ confidence level which gave a Mantel-Haenszel chi2 (1) of 753.57 $\operatorname{Pr}>\operatorname{chi}^{2}=0.0000$. All the zones had antibodies greater than $76 \%$ except Banadir and north-western zones that had sero-prevalence values of 58 and $73 \%$ respectively. The overall post vaccination serum antibody level observed in Somalia was much higher than that observed by Faris et al. (2012) in a cross-sectional epidemiological study conducted in selected districts in Ethiopia. A similar vaccine made from the same Nigeria 75/1 strain from National Veterinary Institute in Debre-Zeit, Ethiopia, gave a relatively lower post vaccination seroconversion of $61 \%$, which was attributed to the poor handling of the cold chain Faris et al. (2012).

The overall unit cost of PPR vaccination in Somalia, 2012, was estimated as USD 0.28 per animal. This is much less than the overall individual animal vaccination cost for Rinderpest from a study by (Tambi et al. 1999) which estimated the individual animal vaccination cost as ECU 0.42 equivalent of USD 0.51 based on average ECU value between 1989 and 1996. In the same study, unit cost of Rinderpest vaccination in Ethiopia was estimated as ECU 0.27 (USD 0.33) and this relatively low unit cost was attributed to economies of scale. The estimated cost of a dose of PPR vaccine in Somalia was USD 0.12 which compares favourably with the USD 0.10 reported by Jones et al. (2016) in other parts of Africa. However, the unit cost of service delivery of the PPR vaccine per animal was different. In Somalia, it was USD 0.14 per animal which was much lower than USD 0.3 estimated by Jones et al. (2016). This could have been due to the economy of scale, considering that nearly 20 million sheep and goats were vaccinated against PPR disease. The differences could have also arisen due to different ways of costing the service delivery. In the Somalia study, the cost of service delivery was calculated based on the cost of personnel time and the transport costs during data and serum collection. The procurement of vaccine increased the total cost of vaccination. In this study, it constituted $50 \%$ of the total vaccination cost. One way of reducing this cost is vaccinating against more than one disease that is prevalent in the area. The control of sheep and goat pox and contagious caprine pleuropneumonia diseases could be done alongside PPR disease (Kumar et al. 2014; FAO/OIE 2015).

\section{Conclusions and recommendations}

This paper has provided a detailed account of a successful mass PPR vaccination in Somalia. It has brought out practical implications of PPR control in a conflictaffected and fragile country that can be adopted by other countries. PPR vaccination campaigns in such countries characterised by limited public veterinary personnel can be implemented through involvement of private livestock professional organisations which have operational presence and technical capabilities. In Somalia, the Livestock Professional Associations in Banadir, central and southern Somalia and the Ministries responsible for livestock in the north-eastern and north-western Somalia were contracted to carry out the mass vaccination 
campaigns, which built confidence and improved goodwill with pastoral communities.

Mass vaccination against PPRV in countries endemic with PPR controls the virus circulation in the small ruminant population to a level where targeted vaccination can be considered. Vaccinations carried out before the expected seasonal movements enhance vaccination coverage. Although funding sources for a PPR disease control programmes are limited in most developing countries, Somalia successfully vaccinated nearly 20 million sheep and goats against PPRV within a livelihood support programme framework. The capacity of public and private veterinary services in Somalia was enhanced through country-wide provision of cold chain facilities and vaccination equipment, which is anticipated to further reduce the cost of vaccination delivery in the future. Furthermore, where there was insufficient cold chain, arrangements were put in place to share cold chain facilities between human and animal vaccines under the "One Health" programme which reduced the frequency of replenishing the ice-packs to two to three days. Despite Somalia not having the capacity to produce PPR vaccine, it was still possible to source a good quality vaccine certified by AU-PANVAC from external sources at a competitive cost of USD 0.12. It was possible to determine the effectiveness of the mass vaccination through two serological surveys. The cost of the pre-vaccination survey was significantly reduced by using the PPR vaccination teams to collect the sero-surveillance serum samples prior to vaccination. The analyses of the serum samples were carried out at the AU-PANVAC laboratory. Somalia attained a herd immunity threshold of $76 \%$ through the country-wide mass PPR vaccination programme of nearly $60 \%$ of the national small ruminant population. This was shown to stabilise the virus within the target population as there were no reported clinical cases of the disease.

The focus should therefore be to increase the herd immunity threshold to $80 \%$ as a way of reducing virus circulation, considering the high turnover, uncontrolled movements and the new annual introduction of naïve population. This should be achieved through annual targeted vaccination based on extensive epidemiological surveillance. It will be worthwhile to target only sheep and goat above three months with no history of PPR vaccination. Further investment should be made on solar powered cold chain facilities to increase penetration of the vaccines to the remote rural vaccination sites. This will not only reduce the transport cost of replenishing the ice packs but shall also improve the seroconversion rates due to better cold chain maintenance. Somalia should invest in laboratory facilities for confirming disease cases and monitoring PPR herd immunity levels. Further studies should be conducted to improve the understanding of the role of wild and other domestic ruminants in the maintenance of peste des petits ruminants virus (PPRV).

\begin{abstract}
Abbreviations
AU-PANVAC: African Union's Pan African Veterinary Vaccine Centre; BENALPA: Banadir Livestock Professional Association; c-ELISA: Competitive Enzyme-Linked Immunosorbent Assay; CERELPA: Central Region Livestock Professional Association; ELISA: Enzyme-Linked Immunosorbent Assay; FAO: Food and Agriculture Organisation of the United Nations; FMT: Form Monitoring Tool; IGAD: Inter Governmental Authority for Development; JOVAC: Jordan-based Vaccine Production Company; MoLAH: Ministry of Livestock and Animal Husbandry; MoLFR: Ministry of Livestock, Forestry and Range; OIE: World Animal Health Organisation; PPR: Peste de Petits Ruminants; PPRV: Peste de Petits Ruminants Virus; SAHSP: Somalia Animal Health Project; SOWELPA: South West Livestock Professional Association; TCV: Total cost of the vaccination; UNICEF: United Nations Children Fund
\end{abstract}

\section{Acknowledgements}

The support of the Ministries responsible for livestock in Somalia to allow the work to be carried out in Somalia and the paper to be published is highly acknowledged. The authors give thanks to Somalia livestock owners for their cooperation during serum sample collection. The authors give many thanks to the veterinarians and animal health auxiliaries in Somalia for their support during the field work. The authors give gratitude to Mr. Daniela Donati, FAO Somalia representative (acting) in Somalia, and Mr. Rudi VanAaken, FAO Somalia Head of Programme, for their support to have the paper published. The technical support of Dr. Bouna Diop from FAO/OIE PPR Global Secretariat and Dr. Massimo Castiello for the technical input during drafting of the paper is gratefully acknowledged.

Many thanks to Charles Bodjo of AU-PANVAC in Addis Ababa, Ethiopia, for his support in analysing the serum samples. The support of Ms. Baru Adan and Ms. Jeniffer Kariuki of FAO Somalia for their input in analysing the data and producing the map is acknowledged.

\section{Funding}

This paper is based on FAO work funded by various government institutions and funding agencies that include Belgium, Switzerland, Australia, Spain, UK, World Bank, and UN-OCHA. The findings, conclusions and recommendations contained are exclusively from the authors and do not in any way reflect positions or policies of FAO and the above-mentioned government institutions and funding agencies. The funds were used to purchase the PPR vaccines, supplies and equipment, contract out vaccination services and supplement salaries or honoraria of the authors. There was no additional external funding received for this work. The authors are employees of FAO and were involved in the design of the vaccination campaign, data analysis, decision to publish and preparation of the manuscript.

\section{Authors' contributions \\ $\mathrm{SN}, \mathrm{KS}, \mathrm{JM}$ and $\mathrm{CB}$ designed the study. SN, KS and JM undertook the fieldwork. SN, SM JM and KT analysed the data and drafted the original manuscript with further input from KS and CB. All authors read and approved the final manuscript.}

\section{Authors' information}

SN is a veterinary epidemiologist and economist, and a postdoctoral researcher working on animal disease surveillance systems and transboundary animal disease control at the Food and Agriculture of the United Nations (FAO) in Somalia. KS is a veterinarian and researcher working as the livestock sector emergency and programme coordinator at the FAO in Somalia. SM is a veterinarian and postdoctoral researcher working at FAO at the time of the study and now a livestock consultant. JM is animal health officer at FAO in Somalia and is working on tropical animal health research at the Institute of Tropical Medicine, Antwerp, Belgium. CB is a veterinarian and a livestock specialist working as the livestock sector coordinator at FAO in Somalia at the time of the study and now working at FAO office for Central Africa. $K T$ is an economist currently working as information and knowledge management officer at the FAO in Somalia. 


\section{Ethics approval and consent to participate}

Written approval for undertaking PPR vaccination, serum sample collection and shipping of samples to PANVAC was granted by respective Ministries responsible for livestock in different regions of Somalia in 2012. The livestock owners were sensitised on the importance of vaccination and serological survey after which they gave their verbal consent for the activities to be undertaken. The livestock owners were required to append their thumb print on the vaccination form as a proof of consent as most of them were illiterate

\section{Competing interests}

The authors declare that they have no competing interests.

\section{Publisher's Note}

Springer Nature remains neutral with regard to jurisdictional claims in published maps and institutional affiliations.

\section{Author details}

${ }^{1}$ Food and Agriculture Organisation of the United Nations (FAO), Somalia Country Office, P.O Box 30470-00100, Nairobi, Kenya. ${ }^{2}$ P.O Box 4810-00506, Nairobi, Kenya. ${ }^{3}$ Food and Agriculture Organisation of the United Nations (FAO), Sub regional Office for Central Africa, P.O Box 2643, Libreville, Gabon.

\section{Received: 22 January 2018 Accepted: 25 April 2018}

\section{Published online: 30 May 2018}

\section{References}

Ata, F.A., H.S. al Sumry, G.J. King, S.I. Ismaili, and A.A. Ata. 1989. Duration of maternal immunity to peste des petits ruminants. The Veterinary Record 124: 590-591 [PubMed].

Balamurugan, V., D. Hemadri, M.R. Gajendragad, R.K. Singh, and H. Rahman. 2014. Diagnosis and control of peste des petits ruminants: A comprehensive review. Virus 25 (1): 39-56. https://doi.org/10.1007/s13337-013-0188-2.

Banyard, A.C., S. Parida, C. Batten, C. Oura, O. Kwiatek, and G. Libeau. 2010. Global distribution of peste des petits ruminants virus and prospects for improved diagnosis and control. Journal of General Virology 91: 2885-2897.

Bidjeh, K., C. Diguimbaya, P. Hendrikx, V. Debet, D. Tchari, and Naissinger S. 1999. Maternal immunity in young goats or sheep whose dams were vaccinates with anti-peste des petits ruminants. Cahiers Agriculture 3: 219-222.

Chavan, V.V., S.U. Digraskar, S.N. Dhonde, and S.N. Bedarkar. 2009. Seromonitoring of peste des petits ruminants (PPR) in goats (Capra hircus) of Parbhani region of Maharashtra. Veterinary World 2 (8): 299-300.

Couacy-Hymann, E., K. Bidjeh, A. Angba, J. Domenech, and A. Diallo. 1995 Protection of goats against rinderpest by vaccination with attenuated peste des petits ruminants virus. Research in Veterinary Science 59: 106-109. https://doi.org/10.1016/0034-5288(95)90041-1.

Diallo, A. 1988. Peste bovine et peste des petits ruminants: des menaces constantes contre l'élevage dans beacoup de pays en development. Impact: Science et Société 150: 191-204.

Diallo, A. 2004. In Vaccination for the control of peste des petits ruminants. Control of infectious animal diseases by vaccination: 13-16 April 2004; Buenos Aires, Argentina, ed. A. Schudel and M. Lombard, 93-98. Bale: Karger Google Scholar.

Ekue, N.F., V.N. Tanya, C. Ndi, and J.T. Saliki. 1992. Seroprevalence of peste des petits ruminants (PPR) virus in small ruminants in Cameroon. Bulletin of Animal Health and Production in Africa 40 (1): 49-53.

FAO. 2001. Internal FAO vaccination reports.

FAO. 2009a. EMPRES; transboundary disease bulletin 33. Accessed on 12th November 2009.

FAO. 2009b. Livelihood baseline analysis Baidoa-Urban. FSNAU technical series report no. VI 22.

FAO. 2010. Deadly animal virus peste des petits ruminants threatens to spread to Southern Africa. Goal Geology, viewed 16 January 2011, from -animal-viruspeste-des-petits-ruminants-threatens-to-spread-to-southern-africa/8302/.

FAO. 2011 a. Consultancy report by P. B. Rossiter.

FAO. 201 1b. Livelihood baseline analysis Addun pastoral. FSNAU technical series report no. VI 38.

FAO. 2011c. Baseline profile Nugal Valley pastoral (sheep and camel) FSNAU technical series report no. VI 2.

FAO/OIE. 2015. Global control and eradication of peste des petits ruminants. Investing in veterinary systems, food security and poverty alleviation.

Faris, D., A. Yilkal, G. Berhec, and B. Kelay petits. 2012. Seroprevalence and seroconversion after vaccination against peste des ruminants in sheep and goats from Awash Fentale District, Afar, Ethiopia. Preventive Veterinary Medicine 103 (PubMed): 157-162.

Gargadennac, L., and A. Lalanne. 1942. La peste des petit ruminantis. Bulletin des Service Zootechniques et des Epizooties de l'Afrique Occidentale Francaise 5: 16-21.

IGAD 2014: The IGAD Regional peste des petits ruminants (PPR) progressive control and eradication strategy. https:/icpald.org/wp-content/uploads/ 2016/01/Progressive-Control-and-Eradication-Strategy-1.pdf.

Jones B.A., Rich K.M., Mariner J.C., Anderson, J., Jeggo, M., Thevasagayam S., Cai Y. Peters, A.R., and Roeder, P. 2016. The economic impact of eradicating peste des petits ruminants: A benefit-cost analysis. PLoS One 11 (2):e0149982. https://doi.org/10.1371/journal.pone.0149982.

Karimuribo, E.D., Loomu, P. M., Mellau, L.S.B. and Swai, E.S. 2008. Retrospective study on sero-epidemiology of peste des petits ruminants before its official confirmation in northern Tanzania in 2008. Department of Veterinary Medicine and Public Health, Sokoine University of Agriculture, Morogoro Tanzania; Veterinary Investigation Centre (VIC), Arusha, Tanzania. http://agris.fao. org/agris-search/search.do?recordID=DJ2012071861. Accessed 14 Dec 2016.

Kaukarbayevich, K.Z. 2009. Epizootological analysis of PPR spread on African continent and in Asian countries. African Journal of Agricultural Research 4 (9): 787-790. Available online at https:/www.researchgate.net/publication/ 287718287_Epizootological_analysis_of_PPR_spread_on_African_continent_ and_in_Asian_countries. Accessed 14 Dec 2016.

Kihu S M., Gachoki J., Ndungu, E.K., 5, Gitao,C. G., Bebora, L.C., Njenga M.J. ,Gidraph, G.W., Ndichu, M.1., Wahome, R.G., and R. Ireri. 2015. Seroepidemiology of peste des petits ruminants virus infection in Turkana County, Kenya. https://doi.org/10.1186/s12917-015-0401-1.

Kihu, S.M, Gitao, G., and Bebora, L.C. 2015. Peste des petits ruminants disease in Turkana, Kenya. Risk factors, socio-economic impacts and disease control. Publisher: LAP-LAMBERT academic publishing.

Kihu, S.M., L.M. Njagi, G.N. Njogu, J.N. Kamande, and C.G. Gitao. 2012. Peste des petits ruminants in Kenya; pastoralist knowledge of the disease in goats in Samburu and Baringo Counties. Research Opinions in Animal \& Veterinary Sciences 2 (11): 544-553.

Kumar, N., Sunil Maherchandani, Sudhir Kumar Kashyap, Shoor Vir Singh, Shalini Sharma, Kundan Kumar Chaubey, and Hinh Ly. 2014. Peste des petits ruminants Virus Infection of Small Ruminants: A Comprehensive Review. Virus 6: 2287-2327. https://doi.org/10.3390/v6062287 ISSN 1999-4915. Available: https:/www.ncbi.nlm.nih.gov/pmc/articles/PMC4074929/.

Libeau, G., C. Prehaud, R. Lancelot, F. Colas, L. Guerre, D.H.L. Bishop, and A. Diallo. 1995. Development of a competitive ELISA for detecting antibodies to the peste des petits ruminants virus using a recombinant nucleoprotein. Research in Veterinary Science 58: 50-55.

McCarney, S., Robertson, J., Arnaud, J., Lorenson, K., and Lloyd, J. 2013. Using solar-powered refrigeration for vaccine storage where other sources of reliable electricity are inadequate or costly. Vaccine 31 (51): 6050-6057. https://ac.els-cdn.com/S0264410X13010670/1-s2.0-S0264410X13010670-main. pdf?_tid=8c2e0531-6f77-41d2-90a5-32842cf6f147\&acdnat=1526045115_ 7c44ff89e2935ede6dfba69280258d9b.

Megersaa, B., D. Biffaa, T. Belinaa, E. Debelaa, A. Regassaa, F. Abunnaa, T. Rufaelc, S.M. Stubsjøend, and E. Skjerveb. 2011. Serological investigation of Peste des Petits Ruminants (PPR) in small ruminants managed under pastoral and agropastoral systems in Ethiopia. Small Ruminant Research 97 (1-3): 134-138.

Munir, M., Zohari, S., Berg, M. 2013. Molecular biology and pathogenesis of Peste des Petits ruminants virus. Springer Briefs in Animal Sciences 2013: 151. http://eastazar. ivo.ir/Portal/File/ShowFile.aspx?ID=df774181-4e83-4cea-aa76-39b07c3679d2.

OIE 2004: OIE Manual of diagnostics Tests and vaccines for Terrestrial Animals Fifth edition, 2004. https://www.oie.int/doc/ged/D6460.PDF.

Roeder, P.L., G. Abraham, G. Kenfe, and T. Barrett. 1994. Peste des petits ruminants in Ethiopian goats. Tropical Animal Health and Production 26: 69.

Rossiter, P.B., and A.D. James. 1989. An epidemiological model of rinderpest: II. Simulations of the behavior of rinderpest virus in populations. Tropical Animal Health and Production 21: 69-84.

SAHSP. 2006a. Baseline investigation of the Peste des Petits ruminants (PPR) situation in Somaliland. Technical report, 15. East Africa, Nairobi: Terra Nuova.

SAHSP. 2006b. Baseline investigation of the Peste des Petits ruminants (PPR) situation in Puntland State of Somalia. Technical report, 15. East Africa, Nairobi: Terra Nuova.

SAHSP. 2009. Baseline seroprevalence of PPR in Central and Southern Somalia. Technical report. East Africa: Terra Nuova.

Singh, R.P. 2011. Control strategies for peste des petits ruminants in small ruminants of India. Revue Scientifique et Technique 30 (3): 879-887 [PubMed] 137]. 
Stata ${ }^{\circledR}$ Statistical Software. 2013. Stata ${ }^{\circledR}$ statistical software, release 13, StataCorp. Stata. College Station, TX: StataCorp LP.

Tambi, E.N., W. Maina, A.W. Mukhebi, and T.R. Randolph. 1999. Economic impact assessment of rinderpest control in Africa. Revue Scientifique et TechniqueOffice International des Épizooties 18 (2): 458-477.

Taylor, W.P., S. Al Busaidy, and T. Barrett. 1990. The epidemiology of peste des petits ruminants in the Sultanate of Oman. Veterinary Microbiology 22: 341-352.

Thrusfield, M. 2005. Veterinary epidemiology. Third edition @ 2005, 2007 by Blackwell Science Ltd, a Blackwell Publishing company.

Wamwayi, H.M., P.B. Rossiter, D.P. Kariuki, J.S. Wafula, T. Barrett, and J. Anderson. 1995. Peste des petits ruminants antibodies in East Africa. Veterinary Record 136: 199-200.

Waret-Szkuta, A., R. François, D. Chavernac, Y. Laikemariam, G. Libeau, D.U. Pfeiffer, and J. Guitián. 2008. Peste des Petits Ruminants (PPR) in Ethiopia: Analysis of a national serological survey. BMC Veterinary Research 4: 34.

\section{Submit your manuscript to a SpringerOpen ${ }^{\odot}$ journal and benefit from:}

- Convenient online submission

- Rigorous peer review

- Open access: articles freely available online

- High visibility within the field

- Retaining the copyright to your article

Submit your next manuscript at $\gg$ springeropen.com 